\title{
LA DERROTABILIDAD DE LA NORMA JURÍDICA A LA LUZ DEL POSITIVISMO JUDICIAL
}

\author{
THE DEFEATABILITY OF THE LEGAL STANDARD IN THE LIGHT OF \\ JUDICIAL POSITIVISM
}

José Julio Goicochea Elías* Universidad Femenina del Sagrado Corazón Lima-Perú https:/ / orcid.org/0000-0002-4735-8566 josegoicocheae@unife.edu.pe

\section{Resumen:}

El objetivo de este artículo es tratar de determinar hasta qué punto se encuentran los jueces comprometidos con el desarrollo normativo, analizando las consecuencias que ello puede traer si de por medio se encuentran en juego principios superiores o intereses fundamentales. La gran interrogante es si deben morir en el texto de la norma o si deben dar un paso adelante buscando obtener a través del derecho la justicia. Hoy en día los jueces ya no son más la boca muda de la ley sino más bien participantes activos del conflicto social a través de sus resoluciones. Sobre todo, si tienen que resolver procesos relacionados al Derecho de las Familias. Su labor debe estar centrada en buscar aplicar la justicia cuando las leyes no le den la solución a un caso concreto y no estar con temor por la posibilidad que se les aperture un proceso disciplinario.

Palabras Claves: Reglas, Principios, Discrecionalidad, Justicia, Derecho

\section{Abstract}

The objective of this article is to try to determine to what extent are the judges committed to regulatory development, analizyng the consequences that this can brin if higher principles or fundamental interests are at stake. The big question is whether they should step forward seeking to obtain justice through law. Today, judges are no longer the silent mouth of the law but rather active participants in social conflict through their resolutions. Above all, if they have to solve processes related to Family Law. Their work should be focused on seeking to apply justice when the laws do

Doctor en Derecho. Docente de la Facultad de Derecho de la Universidad Femenina del Sagrado Corazón. Miembro Honorario de los Ilustres Colegios de Abogados de Tacna y de la Selva Central. Orden al mérito Francisco de Paula González Vigil por el Ilustre Colegio de Abogados de Tacna. Docente de la UNIFÉ 
not provide a solution to a specific case and not be afraid of the possibility that a disciplinary process will be opened to them.

keywords: Rules, Principles, Discretion, Justice, Law.

\section{LIMINAR NECESARIO}

Con Fecha 19.12.2016 aparece publicado en el Diario Oficial El Peruano el Decreto Legislativo $\mathbf{N}^{\circ} \mathbf{1 3 0 0}$ que regula el procedimiento especial de conversión de penas privativas de libertad por penas alternativas en ejecución de condena. La finalidad de la norma es posibilitar la reinserción de los confinados sentenciados a penas privativas de la libertad que no excedan de los 6 años y que cumplan con ciertos requisitos establecidos por la norma precitada; el artículo $3^{\circ}$ del referido texto legal precisa que procede el procedimiento de conversión de la pena de oficio o a petición de parte para los confinados bajo dos condiciones: i) cuando se les ha condenado a una pena privativa de libertad no mayor a 4 años y se encuentren en el régimen ordinario cerrado del sistema penitenciario y ii) cuando se les haya impuesto una pena privativa de libertad no mayor a 6 años y se encuentren en la etapa de mínima seguridad del régimen ordinario cerrado del sistema penitenciario.

En ese orden de ideas, el ciudadano Jhordan Torres Ríos privado de su libertad por haber sido condenado en un proceso de omisión a la asistencia familiar solicita al operador jurisdiccional del $3 \mathrm{er}^{\circ}$ Juzgado Unipersonal de Lima Norte, Abel Pulido Alvarado el beneficio penitenciario de conversión de la pena. El pago que debía acreditar el sentenciado para acceder al beneficio solicitado era como sigue: $\mathrm{S} / .3,799.38$ por concepto de pensiones devengadas de alimentos y $\mathrm{S} / \mathbf{3 5 0 . 0 0}$ como reparación civil que sumados daban una suma total de $S / . \mathbf{4 , 1 4 9 . 3 8}$ soles. El sentenciado a través del letrado que lo patrocina consigna la suma de $S / . \mathbf{4 , 1 3 0 . 0 0}$ soles sin consignar la diferencia de $S / .19 .38$ que corresponde a los intereses generados por las pensiones devengadas.

La Resolución $\mathrm{N}^{\circ} 2$ expedida por el Magistrado Abel Pulido Alvarado señala que el pedido debe desestimarse por no haber abonado íntegramente el pago de los devengados. En buena cuenta lo que nos estaba señalando el juez era que la libertad de un ser humano vale menos de $S / .20 .00$ soles. Se podría señalar que el magistrado aplicó el derecho de manera estricta, pero la pregunta que surge de inmediato es si los Jueces más que aplicar el derecho deben propender a buscar la justicia. 
Lo más preocupante es que no se plantea en ningún extremo del Decreto Legislativo $\mathrm{N}^{\circ} 1300$ que se requiere la cancelación de la obligación adeudada para acceder al beneficio de conversión de la pena. El juez ha hecho distinción donde la ley no la hace.

Trabajar en un expediente es sin duda analizar los documentos, pero es también un intento de hacerle decir algo, torturarlo, revolverlo en todos los sentidos, analizándolo a la luz de la controversia. Sin embargo, la metáfora del nacimiento es quizás preferible a la de la tortura. El trabajo de un expediente mediante las técnicas de la invención evoca sobre todo aquel de una madre que da a luz a un niño. (Martineau, 2010 p. 32)

\section{LAS REGLAS CONTRA LOS PRINCIPIOS - UNA DISCUSIÓN ATRAPANTE}

El Derecho como vaso comunicante para alcanzar la justicia. Lo primero que cabe analizar es señalar que los jueces han dejado de ser la boca muda de la ley; personajes tenebrosos que se limitaban a aplicar la misma partiendo del hecho que si el legislador no la había previsto era porque la cuestión controvertida no tenía relevancia y que si la tenía la misma no adquiría connotación jurídica.

Como lo diría Guibourg (2011, citado por Alarcón Cabrera y Vigo p.234) al referirse a la ciencia del derecho el mismo puede entenderse "como un juego cuyas reglas determinan cómo se hacen los goles. Estas reglas pueden aplicarse por consenso, ya que son conocidas por todos los jugadores, o bien puede introducirse la figura del árbitro. Cuando hay un árbitro, solo él queda habilitado para determinar si hubo o no hubo gol, y las opiniones de los demás se vuelven irrelevantes, aunque el árbitro se haya equivocado. Ahora bien, si el árbitro se toma sus facultades demasiado libremente y adopta el hábito de decidir en conflicto con las reglas, puede ocurrir una de dos cosas: que los jugadores acepten sus decisiones (y entonces empieza a jugarse otro juego, definido por el árbitro) o que no las acepten (y entonces se mantiene el juego, pero sin árbitro o con otro árbitro). En otras palabras, el poder de los jueces (y, entre ellos, la función interpretativa) no conoce límites dentro del sistema jurídico".

Se considera al juez como un ser omnisciente, que su formación, así como su experiencia, lo han convertido en un portador de una suerte 
de sabor teórico universal, que lo pondría a salvo de cometer un error por ignorancia. Los derechos del justiciable estarían así garantizados. (Martineau, 2010 p.169)

La resolución judicial que ha servido como punto de partida del presente artículo adolece de dos criterios elementales del derecho procesal: la proporcionalidad y la razonabilidad. No interesa analizarla desde la óptica de la pandemia que nos viene azotando. Su falta de congruencia va más allá de cualquier caso fortuito. Afecta no solo a la libertad de la persona humana comprendida como derecho fundamental, sino que también atenta colateralmente contra los derechos del menor alimentista. Sería bueno que los jueces como requisito previo al acceso a la función jurisdiccional pudieran pasar una noche en un pabellón de alta peligrosidad a ver si siguen manteniendo ese criterio. El Derecho Penal es uno de mínima intervención, donde la cárcel jamás puede ser considerada como regla, sino más bien como una excepción. Queda claro para el autor que el Derecho Penal no es la última ratio porque tiene otras medidas: grilletes electrónicos, condena suspendida, arresto domiciliario que lo ayudar a cumplir su finalidad de elemento de control social: la prisión que implica en la realidad de las cosas, dentro de una jaula (porque eso y no otra cosa son las celdas), esa es la última ratio.

La proporcionalidad es una construcción jurídica. Ella es un instrumento metodológico. La proporcionalidad está compuesta por cuatro componentes: el fin adecuado, la conexión racional, los medios necesarios y la relación adecuada entre el beneficio ganado con la realización del fin adecuado y la vulneración causada al derecho fundamental (este último componente se denomina también "proporcionalidad en sentido estricto" (ponderación). Estos cuatro componentes constituyen el núcleo de la cláusula restrictiva. Ellos son cruciales para la comprensión de la proporcionalidad. (Barak, 2017 p. 159)

La razonabilidad no está atada a una lógica deductiva. Por el contrario, ella se determina con base en la identificación de las consideraciones relevantes y su ponderación de acuerdo con su peso (Barak, 2017 p.410)

Por consiguiente, una decisión es razonable si se ha llegado a ella con posterioridad a la asignación del peso adecuado a cada uno de los diversos factores que deben haber sido considerados y si dicha decisión pondera de manera adecuada los diversos factores 
relevantes. En la médula de la razonabilidad se encuentra la noción de ponderación (Barak, 2017 p.411)

Diferenciar las reglas de los principios es clave para poder comprender el nudo giordano del tema materia del presente artículo. El magistrado cuya resolución analizamos ha resuelto en aplicación estricta del texto de la norma. El problema es que ese criterio por legalista no deja de ser válido. Pero, por otra parte, queda claro que no se compromete con el derecho a la libertad y los que le son colaterales en este caso: la vida, el trabajo, la salud, y el interés superior del niño. La facultad sancionadora (ius puniendi) del Estado no puede ser entendida como una espada damocliana que pende sobre la cabeza de todos los ciudadanos.

Ahora bien, se puede convenir que una regla es un enunciado condicional que conecta una determinada consecuencia jurídica a una clase de hechos: "Si F, entonces G".

El concepto de principio, por el contrario, es algo más complicado $\mathrm{y}$, por otra parte, bastante controvertido. Se puede adelantar provisoriamente que en nuestra cultura jurídica se consideran principios aquellas normas que presenten conjuntamente dos características:

(i) Por un lado, que tengan carácter fundamental y,

(ii) Por otro lado, que estén sujetas a una peculiar forma de indeterminación. (Guastini, 2014 p.184)

Como lo diría García Figueroa (2014, citado por Gascón Abellán, $\mathrm{p}, 211)$ "la teoría de la argumentación de Robert Alexy se basa en una sencilla idea, la llamada "tesis del caso especial" (Sonderfallthese). Según la tesis del caso especial, el razonamiento jurídico es un caso especial del razonamiento práctico general. ¿Qué significa esto? Significa que el razonamiento jurídico queda definido per genus et differentiam de modo que, perteneciendo al género del razonamiento moral, se diferencia de otros de su género por estar sometido a ciertas restricciones institucionales. Por tanto, la matriz del razonamiento jurídico es moral, aunque ese razonamiento moral cuente con unos límites nada desdeñables, los impuestos por la ley, el precedente y la dogmática jurídica".

Por otro lado, si dejamos de lado la rigidez del pronunciamiento de la decisión del Magistrado: esto es si prescindimos de los S/.19.38, 
técnicamente se estaría aplicando una doble sanción a un ciudadano por el mismo hecho, algo que en modo alguno puede permitirse en un estado constitucional de derecho. A quien ya estaba purgando condena por no haber abonado la suma, se le retiene su derecho a la libertad cuando ha satisfecho el $\mathbf{9 9 . 5 3 \%}$ del monto ordenado en la resolución judicial. ¿En qué armario ha quedado guardada la sana crítica del magistrado en cuyo despacho tuvo la mala fortuna de caer el expediente del sentenciado?

Así tenemos que Álvarez (2011, citado por Alarcón Cabrera y Vigo, p.57) señala al referirse a los argumentos que "son esenciales porque cuando hemos llegado a una conclusión que está fuertemente asistida por razones, los argumentos son los modos de explicar y de defender esas razones. En tal sentido un argumento no se agota en repetir las conclusiones expresadas. Por el contrario, ofrece razones y evidencias para que cualquiera pueda llegar a la conclusión defendida. Este es el único modo en que se puede convencer a los demás, exhibiendo las razones y las evidencias que lo convencieron al que decide para llegar a la conclusión expresada. No es un defecto tener un fuerte punto de vista respecto de algo. Lo que es lamentable es tener solamente eso".

Una de las razones por las cuales el Poder Judicial es una de las instituciones más criticadas es precisamente por decisiones como esta que esta desafectada de un razonamiento principista se limitan a ejecutar lo legislado sin el menor ejercicio de desarrollo argumentativo y/o interpretativo.

Uno de los principales problemas que se presentan en las escuelas de derecho de pre y posgrado es que las mallas curriculares no incluyen el curso de argumentación jurídica como uno obligatorio. Craso error. Si asemejáramos el derecho a la religión nos encontraríamos ante un pecado mortal. La experiencia profesional nos ha mostrado que en una gran mayoría los jueces son positivistas. Se cierran en la aplicación formal de la ley, Aprecian el árbol, pero no distinguen el bosque. Se pierde de vista que el legislador da la norma en un contexto temporal. No tiene la capacidad de ver más allá de lo evidente.

La teoría de la argumentación jurídica tiene un desarrollo sostenido a partir del ecuador del siglo próximo pasado, como consecuencia de un planeta que se encontraba en guerra. Se habían cometido crímenes horrendos: gente que era ingresada viva a hornos crematorios; poblaciones enteras que eran exterminadas por un criterio absurdo de supremacía racial; familias enteras que eran encerradas en cámaras de gas; y así por el estilo, 
aunque como no todo es perfecto no se llevó a tribunales a los responsables del exterminio de poblaciones enteras con el arrojo de dos bombas atómicas en las ciudades japonesas de Hiroshima y Nagasaki. Alguna vez escribió George Orwell que la historia la escriben los vencedores.

El profesor español Atienza al referirse a la concepción material de la argumentación nos enseña que

Y la concepción material constituye el núcleo de la justificación que llevan a cabo los jueces: la obligación de motivar no se justifica simplemente mostrando que la decisión (o el correspondiente enunciado de deber) es la consecuencia lógica de ciertas premisas, ni tampoco por razón de que sea aceptable para cierto auditorio, sino que exige (de manera esencial) que se trate de buenas razones, según los criterios de racionalidad característicos de una teoría de las fuentes, de la validez, de la interpretación, etcétera..... O sea, una cosa sería dar cuenta de los motivos (en el sentido de los factores causales) de diverso tipo que llevan a un juez o a un tribunal a tomar una determinada decisión; y otra señalar las razones que permiten considerar esa decisión como algo aceptable, justificado. En otros términos: una cosa son las razones que explican la decisión, y otra las que la justifican. La palabra "motivar" puede utilizarse en los dos sentidos, pero cuando se dice que los jueces tienen la obligación de motivar sus decisiones, lo que quiere decirse es que deben justificarlas. (Atienza, 2013 pp. 114-115)

El derecho como ciencia es la más relativa de todas las ciencias sociales. No es un producto de laboratorio. Cambia como la letra de la canción que nos regala la negra Mercedes Sosa. Seria iluso pretender que la interpretación literal resuelva todos los problemas que se le presenten a los jueces. Es más, cualquier persona lega en derecho podría administrar justicia a nombre de la nación. Lejos estamos de habitar el mismo país que Alicia: el de las maravillas.

Schecaira , Struchiner (2019 p.113) arriesgan un concepto cuando indican que una manera relativamente radical de oponerse a la rigidez del textualismo sería afirmando que la interpretación de un texto legal debe ser realizada siempre a la luz de los fines o propósitos implícitos en el texto. 


\section{LA INTERPRETACIÓN Y LA INTEGRACIÓN DE LA NORMA JURÍDICA}

Si establecemos como punto de partida que los jueces no pueden dejar de administrar justicia por vacíos o deficiencias en el texto de la norma, y que en muchas ocasiones se encuentran ante casos difíciles de resolver podemos ir comprendiendo la dimensión del problema. Es preocupante por decir lo menos, como para un gran número de magistrados el sentido común es el menos común de todos. El hecho que ante situaciones similares se apliquen criterios diferenciados afecta directamente a la predictibilidad de las resoluciones judiciales y a la seguridad jurídica.

Si bien es cierto que la regla siempre va a partir con ventaja sobre los principios, porque es imposible pensar en un mundo sin leyes: sería regresar a los tiempos de las cavernas y la autocomposición donde primaba la ley del más fuerte y la vida no valía nada.

Toda norma tiene no menos de "cinco dimensiones temporales"

a) La primera se refiere a su existencia jurídica o pertenencia al ordenamiento

b) La segunda se refiere a lo que aquí llamaremos vigencia (en un sentido que deberá ser precisado)

c) La tercera se refiere a su validez

d) La cuarta se refiere a la aplicabilidad por parte de los órganos jurisdiccionales y administrativos

e) La quinta, finalmente, se refiere a lo que aquí llamaremos su eficacia (en un determinado sentido de esta palabra). (Guastini, 2014 p. 267)

Mas adelante agrega el mismo autor:

Una norma es válida si, y solo si:

i) Ha sido producida conforme a las normas (estructuralmente supraordenadas) que regulan su producción, y

ii) Es compatible con las normas (materialmente supraordenadas) que limitan su posible contenido. (Guastini,2014 p. 270)

Nos encontramos ante su sistema normativo que ha perdido su heterogeneidad. El juez se encuentra obligado y comprometido a desarrollar una función generadora de derecho. Se le ha presentado para resolución una 
situación no prevista temporalmente por el legislador. Ergo, una situación atemporal. Un espacio vacío de derecho que debe ser solucionado acudiendo a las fuentes formales del mismo. Si bien es cierto que algunos podrían catalogar este caso como uno difícil no lo considero así. Me parece que no se necesita ser entendido en leyes para darse cuenta de lo descabellado que resulta aplicar en esos casos el contenido de la norma a la situación.

Hasta el momento se ha razonado como si la operación de calificación pudiese hacerse sin dificultad y resultase normalmente de la simple consideración de los elementos constitutivos de una norma jurídica existente, clara y adecuada. Sin embargo, los profesionales en ejercicio saben que casi siempre eso no ocurre, sea porque la norma jurídica no puede aplicarse a una nueva situación de hecho, sea porque el texto de la norma jurídica susceptible de aplicarse es oscuro, poco claro, sea también porque el abogado se encuentra ante definiciones o enunciados contradictorios en una misma norma. (las negritas son nuestras). (Martineau, 2010 p. 177)

La sociedad en su conjunto espera que los magistrados sepan cómo resolver este tipo de operaciones. Que tengan presente que existe una conexión lógico-necesaria entre derecho y moral.

La corrección moral es una propiedad del Derecho. Eso implica sustentar dos tesis básicas:

T1. Una tesis metaética cognitivista: Existe un orden moral objetivo (el denominado "Derecho Natural") que sirve como criterio de valoración moral. Esta es una tesis de la filosofía moral y la tesis central del iusnaturalismo.

T2. La tesis de la vinculación: Existe una relación conceptual necesaria entre el Derecho y ese orden moral objetivo. (Da Rosa, 2019 p. 159)

Cabe preguntarse entonces si el juez debe seguir siendo un mero espectador o si debe pasar a desempeñar un rol más importante, teniendo en cuenta los intereses que se encuentran en juego a la espera de la decisión que tome. En la cuestionada resolución materia de análisis nos queda claro que se debe privilegiar el derecho a la libertad.

Deseo, por lo tanto, repetir las diversas observaciones que realicé sobre la subjetividad y la objetividad en la interpretación literaria. En mi exposición sobre la interpretación jurídica no hay ninguna razón obvia 
para dudar de que una interpretación del derecho pueda ser mejor que otra, y que una pueda ser la mejor de todas. Si esto es o no así depende de cuestiones generales de filosofía que no atañen al derecho más que a la literatura; y, al examinar estas cuestiones generales, no conviene empezar con ideas rígidas sobre las condiciones de objetividad necesarias y suficientes (por ejemplo, que ninguna teoría del derecho puede ser sólida si no es demostrablemente sólida, si no es capaz de arrancarle su aprobación a las pruebas). (Dworkin, 2012 p. 211)

Es interesante también anotar que el profesor español García Amado a pesar de ser uno de los enemigos más recalcitrantes de la ponderación en el derecho, no deja de asombrarnos cuando se aparta de una posición tan rígida y la pone por escrito en un texto de su autoría.

Si acaso, queda solamente el detalle diferenciador de que las normas legisladas, que generalmente van a ser vistas como reglas y no como principios, tienen una preferencia prima facie frente a los puros principios, sean expresos o implícitos. Esa preferencia prima facie significa que se les supone inicialmente más peso, y así se explica que las más de las veces deban ser aplicadas y no derrotadas en el caso; pero eso no impide que en ciertas ocasiones pueda asignarse mayor peso al principio en su contra concurrente, y, de esa manera, la decisión contra legem es presentada como decisión perfectamente acorde con el ius y con la Constitución misma. (García Amado, 2017 p. 70-71)

Cuando un juez interpreta se despierta del ostracismo al que lo pretende conducir el texto normativo. Lo hace porque se percata que conducir en sentido contrario es someterse a la norma. El derecho, así como también los operadores que trabajan sobre el mismo no pueden permanecer indiferentes a las nuevas transformaciones conductivas que desarrollen los colectivos sociales. Producir para crear. En la actualidad nos encontramos ante una concepción dinámica del derecho donde se han desterrado conceptos cambiando la rigidez de sus patrones. Podríamos citar como ejemplo a que hoy podemos hablar de prueba dinámica cuando nos referimos a la carga de la prueba, ampliando el concepto del onus probandi que heredamos de nuestros maestros del derecho romano.

Sin embargo, es penoso apreciar como en la práctica los jueces emiten resoluciones tan descabelladas por un temor a lo que pueda sostener contra ellos ese cuarto poder que es la prensa.

Una pieza oratoria sublime es la que nos recuerda Martineau (2010) cuando evoca a Vincent de Moro Giafferi cuando proclamaba que: 
Como lo diría Giafferi (2010, citado por Martineau p.201) “¿La opinión pública? ¡Expulse, a esa intrusa, esa prostituta que jala de la manga del juez! Ella, que, al pie del Gólgota, daba los clavos a los verdugos. Ella, aplaudía las masacres de septiembre, y, un siglo más tarde, reventaba con el extremo de su parasol los ojos de los comuneros heridos".

O el mismo autor cuando al referirse a Paul Lombard abogado de Christian Ranucci nos recuerda cuando aquel mencionaba que:

"La opinión pública que golpea la puerta de esta Sala es una prostituta que jala al juez por la manga. Hay que expulsarla de nuestros pretorios. Cuando entra por una puerta, la justicia sale por la otra". (Martineau, 2010 p. 233)

\section{LA PONDERACIÓN}

A estas alturas considero haber dejado establecida mi posición: que al Juez cuya resolución se analiza le falto hacer un desarrollo ponderativo teniendo en cuenta la dimensión de los intereses en juego. No tuvo en consideración que el hecho de seguir privando a un ser humano de su libertad no solamente afecta a aquel, sino también a los niños que dependen de su trabajo para poder obtener su sustento.

Alexy concibe los derechos constitucionales como principios, y los principios como mandatos de optimización, que ordenan que algo debe realizarse en la mayor medida posible (de acuerdo con las posibilidades fácticas y normativas existentes). Cuando se producen conflictos entre derechos (o entre principios; lo cual tiene lugar en todos los campos del Derecho) los mismos deben resolverse aplicando un test de proporcionalidad, o sea aplicando el principio de proporcionalidad que, para Alexy, viene a ser una especie de meta-principio o, si se quiere, el principio último del ordenamiento jurídico. Ese principio consta, a su vez, de tres subprincipios: el de idoneidad, el de necesidad y el de proporcionalidad en sentido estricto o ponderación. Los dos primeros se refieren a la optimización en relación con las posibilidades fácticas. Significa que una medida (una ley, una sentencia, etc. que limita un derecho (un bien de considerable importancia) para satisfacer otro, debe ser idónea para obtener esa finalidad y necesaria, o sea, no debe ocurrir que la misma finalidad pudiera alcanzarse con un costo menor. El tercer subprincipio, por el contrario, tiene que ver con la optimización en relación con las posibilidades normativas. (Atienza, 2018 p. 18) 
A nuestro parecer, no cabe la menor duda que si se realiza un ejercicio ponderativo entre una regla que al final de cuentas justificaría la decisión adoptada por el Juzgador contra el derecho a la libertad, el resultado sería favorable a este último por las razones expuestas precedentemente.

Como lo diría López ( 2011, citado por Alarcón y Vigo pp.287-288) lo que ocurre "cuando el sistema jurídico no prescriba un determinado Derecho, hay que determinar los principios que resultan aplicables, ya que los mismos juegan un papel decisivo para reconocer y proteger los derechos individuales o de grupo, la función de los principios consiste o radica en la limitación o reducción del discrecionalismo de los jueces.(...)El juez en un caso difícil se encuentra en una situación de incertidumbre, no tiene solución en su sistema jurídico, y puede aún identificar principios que prescriben cursos de acción contradictorios. Que el principio oriente significa en la concepción dworkiniana que no es obligatorio.(...) La selección del principio aplicable en el caso difícil resulta de la propiedad de peso que tenga cada uno de los principios en juego, entendiendo por peso la capacidad justificatoria, la posibilidad de fundamentar un caso; Dworkin presupone que hay principios que tienen mayor justificatoria que otros, pero también concibe las situaciones de empate, en ambos casos es el decisor quien debe decidir, y por esta razón ha sido criticada su tesis por cuanto la elección del peso de un principio, o en el supuesto de empate, la resolución se deja en el decisor".

Cabe señalar que la resolución judicial analizada, no era en modo alguno de complicada resolución, y que, a pesar de todas las tesis sustentadas precedentemente, el juzgador optó por continuar dejando privado de su libertad al solicitante, sin sostener criterios de razonabilidad y proporcionalidad. Son discernimientos como este, los que han llevado a la academia de la magistratura a capacitar desesperadamente a jueces y fiscales en temas de argumentación jurídica.

La constitucionalización o principialización de un caso para el que existe una regla legal tiene lugar cuando se confronta el principio constitucional que avala la conducta que se juzga con el principio o derecho constitucional amparado por esa regla legal. En las constituciones de nuestro tiempo es relativamente fácil vincular una regla a un principio o derecho constitucional: casi siempre habrá alguno. Por tanto (casi) cualquier caso puede potencialmente presentarse como un conflicto de principios: basta con poner de relieve el principio o bien constitucional que hay detrás de la regla aplicable y confrontarlo con 
otro principio constitucional que juega en sentido contrario. (Gascón, 2014 p. 314)

\section{PRONUNCIAMIENTOS DEL TRIBUNAL CONSTITUCIONAL CON RESPECTO A LA LIBERTAD}

Por otra parte, existe reiterada jurisprudencia del supremo interprete constitucional que se refiere al derecho de la libertad del ser humano y que es relevante comentar. Así tenemos cuando el Tribunal Constitucional (2006) nos refresca alguna de sus motivaciones

\section{Exp. N² 2496-2005-PHC 17/05/05}

La libertad personal no es solo un derecho fundamental reconocido, sino un valor superior del ordenamiento jurídico, pero su ejercicio no es absoluto e ilimitado; pues se encuentra regulado y puede ser restringido mediante ley. (p. 169)

\section{Exp. N $^{\circ}$ 0019-2005-PI 21/07/05}

El inciso 24 del artículo 2 de la Constitución reconoce el derecho fundamental a la libertad personal. Se trata de un derecho subjetivo en virtud del cual ninguna persona puede sufrir una limitación o restricción a su libertad física o ambulatoria, ya sea mediante detenciones, internamientos o condenas arbitrarias. (p.169)

\section{Exp. $\mathrm{N}^{\circ}$ 1091-2002-HC 12/08/02}

En cuanto derecho subjetivo (el derecho a la libertad personal) garantiza que no se afecte indebidamente la libertad física de las personas, esto es, su libertad locomotora, ya sea mediante detenciones, internamientos o condenas arbitrarias. Los alcances de la garantía dispensada a esta libertad comprenden frente a cualquier supuesto de privación de la libertad locomotora, independientemente de su origen, la autoridad o persona que la haya efectuado. Garantiza, pues. Ante cualquier restricción arbitraria de la libertad personal. (pp. 169-170)

\section{Exp. $\mathrm{N}^{\circ}$ 0019-2005-PI}

Toda previsión que favorezca al derecho subjetivo de la libertad personal más allá de su contenido constitucionalmente protegido, solo resultará válida si no afecta de modo desproporcionado el cuadro 
material de valores reconocido en la Carta Fundamental; es decir, en la medida en que no vacíe los contenidos o desvirtué las finalidades que los otros derechos fundamentales (en sus dimensiones subjetiva y objetiva) cumplen en el ordenamiento jurídico o, en general, aquella que cumplen los bienes esenciales a los que la Constitución explícita o implícitamente concede protección, por resultar imprescindibles para la consolidación de todo Estado social y democrático de derecho, y para que este pueda hacer frente a toda amenaza contra los principios constitucionales en que se sustenta. (p. 170)

\section{Exp. $N^{\circ}$ 0019-2005-PI}

La plena vigencia del derecho fundamental a la libertad personal es un elemento vital para el funcionamiento del Estado social y democrático de derecho, pues no solo es una manifestación concreta del valor libertad implícitamente reconocido en la Constitución, sino que es presupuesto necesario para el ejercicio de otros derechos fundamentales. (p.170)

\section{LA DERROTABILIDAD DE LA NORMA JURÍDICA}

¿Es que acaso la norma escrita brinda solución a todos los casos prácticos? Si así fuera el derecho estaría invadiendo el terreno de las matemáticas. No necesitaríamos de jueces ni fiscales; cualquier ciudadano en pleno uso de sus facultades podría aplicar justicia interpretando los códigos. Haciendo y deshaciendo. No tendrían razón de ser las escuelas o academias jurídicas. Para que capacitar a los jueces y fiscales en algo que se da por sobreentendido, evitando así un fuerte egreso al presupuesto general de la república.

Ródenas (2001, citado por Atienza pp.320-321) al respecto "distingue tres sentidos en los que cabe hablar de derrotabilidad de las reglas, o sea, tres supuestos en los que las reglas dejarían de ser tomadas como razones excluyentes. Uno se produce cuando la derrotabilidad se predica de "la prescripción contenida en la formulación normativa mediante la que la regla se expresa, pero no del balance de razones subyacentes a la misma" (p.74); es lo que ocurre en los supuestos de excepciones o de casos fuera del alcance de las reglas. Otro, al que llama "derrotabilidad radical", tendría lugar cuando "de acuerdo con el Derecho, concurren para basar la respuesta a un problema de indeterminación en criterios extrajurídicos, es decir, criterios ajenos a los que el propio Derecho establece". 
No se puede ser más papistas que el papa y establecer que las reglas no son sometibles a la menor consideración por tener un modelo inmaculado. Seria regresar en el tiempo a la época del derecho romano donde se manejaba el concepto del dura lex sine lex.

Desde el punto de vista de la vinculación al texto constitucional, de la seguridad jurídica y la previsibilidad, el modelo puro de las reglas es, sin duda, la alternativa más atractiva. Sostiene el modelo puro de las reglas quien considera que las normas de derecho fundamental son normas que posiblemente necesitan una complementación, pero que siempre pueden aplicarse sin llevar a cabo una ponderación y, en este sentido, son libres de ponderación. (Alexy. 2012 p.98)

Atienza y Ruiz (2009) acotan que "todo ello es lo que explica el que, a lo largo de la historia de la cultura jurídica, el acento haya ido desplazándose más o menos según los períodos y los sistemas jurídicos, pero situándose siempre en algún punto intermedio, a lo largo de un continuo que va desde el extremo de ver en el Derecho exclusivamente un conjunto de reglas inderrotables -en la terminología de Regan, entender las reglas como absolutamente opacas frente a los principios que las dotan de sentido y las justifican -al extremo de ver las reglas como pautas meramente indicativas que deben ser excepcionadasderrotadas- en cada ocasión en que su aplicación sea incongruente en relación con esos mismos principios- en la terminología de Regan, entender las reglas como absolutamente transparentes en relación con esos mismos principios. De forma que, a nuestro juicio, uno de los criterios centrales desde los que evaluar distintas teorías del Derecho es el de su capacidad para dar cuenta cómo, y en qué punto intermedio, se articula y resuelve la tensión entre lo que podríamos llamar el polo de las reglas -vinculado a la predictibilidad y a la reducción de la complejidad en la toma de decisiones- y el polo de los principios -vinculado a la coherencia valorativa de esas mismas decisiones- " (p. 235)

Como lo apunta Garcon (2010, citado por Martineau,p. 343) “¿Dirían ustedes, jueces franceses qué son menos lamentables? ¿Pueden decir ustedes que el rigor de los textos no les permite ser humanos? Si esa fuese la ley, deberíamos sonrojarnos y mejor valdría no habernos reunido para aplicarla". 


\section{LOS DERECHOS QUE SE VEN AFECTADOS COLATERALMENTE}

Por otra parte, no debemos dejar pasar que son varios los derechos fundamentales que se ven afectados por la resolución del Magistrado como son:

El derecho a la vida: más aún si tenemos en cuenta que estamos atravesando una pandemia que no discrimina color de piel ni billeteras. Es más, el hacinamiento penitenciario es el caldo de cultivo perfecto para el desarrollo del virus. Existe una sobrepoblación penitenciaria en la que incluso una gran cantidad de confinados se encuentran privados de su libertad a pesar de no haber sido sentenciados, por un exceso de aplicación de la medida de prisión preventiva. Los centros de readaptación social no cuentan con la infraestructura necesaria ni con el personal debidamente capacitado para atender a la población penal. Los internos se están muriendo en los penales. Cabe agregar que los hospitales y clínicas que están enfrentando la enfermedad tienen una antigüedad de por lo menos 20 años de construcción.

El derecho a la libertad: Privar a una persona de su libertad es la última ratio. Si igualáramos al derecho penal con la medicina, podemos señalar sin temor a equivocarnos, que se compara a una operación quirúrgica para extraer un tejido del cuerpo, cuando ninguna otra alternativa (pastillas, jarabes, antibióticos etc.) ha surtido efecto. Es decir, al derecho no le queda de otra.

El derecho a la salud: Esta vulneración se produce por la sobrepoblación carcelaria que trae como consecuencia un hacinamiento de la población confinada en los centros de readaptación penal; las prisiones se han convertido en focos infecciosos. Mas aún si se toma en cuenta que a la fecha en que se expide la criticada resolución nos encontramos pasando por una pandemia que viene llevándose la vida de miles de seres humanos; si a ello le sumamos una deficiente infraestructura y la falta de un personal médico especializado podemos darnos cuenta de las dimensiones que ha alcanzado el problema.

El derecho del menor a recibir sus alimentos: Queda claro que es complicado que un menor siga recibiendo los alimentos que por ley le corresponden, si el obligado a prestarlos se encuentra privado de su libertad. Cabe preguntarnos si el principio del interés superior del niño es tal, o tan solo letra muerte. El problema como se tiene dicho, no son las normas, que de sobra tenemos, sino más bien los agentes que tienen que operar sobre las mismas. Es preocupante comprobar que los jueces en un gran número de veces no razonan, simplemente aplican el texto normativo sin desarrollar 
técnicas de argumentación al momento de plasmar su criterio en las resoluciones que expiden.

\section{CONCLUSIONES}

1. El derecho es la más relativa de todas las ciencias sociales. Cambia al ritmo de la evolución de las conductas humanas, por lo tanto, jamás puede ser entendido como un juego de laboratorio con respuestas exactas a cada uno de los casos que son sometidos a su consideración. En ese escenario los jueces no pueden ser los meros ejecutores de la norma escrita, sino que más bien deben ejercer las reglas de la sana crítica para resolver los casos que así lo requieran, cuando la interpretación del texto normativo no les proporcione una salida; tomando en cuenta que las reglas han sido dictadas en un espacio temporal y que no existe sistema jurídico que pueda considerarse heterogéneo y que no les exija la implementación de desarrollo argumentativo para poder integrar el derecho. Comprender que el derecho es atemporal, implica que no se circunscribe a una época determinada. Que como operadores jurisdiccionales deben tener tatuada en su frente aquel verso de Machado: todo pasa y todo queda, pero lo nuestro es pasar, pasar haciendo caminos, caminos sobre el mar.

2. Estando a la conclusión anterior, se tiene que los jueces están obligados a desarrollar ejercicios ponderativos otorgando un peso específico a cada uno de los intereses (principios) que se encuentren en juego para conseguir decisiones justas. Cabe agregar que justicia no es lo mismo que derecho. Este último vocablo se refiere al desarrollo del precepto normativo, aquel al ideal que se pretende alcanzar a través del desarrollo del proceso judicial. Los ciudadanos esperamos que, a través de sus interpretaciones judiciales, los jueces contribuyan a mejor la imagen que se tiene del Poder Judicial.

3. Los jueces deben comprender que en temas de derecho no existe una última palabra. Que hasta los precedentes vinculantes pueden dejar de aplicarse cuando no resuelvan una situación concreta, sin que por ello se pueda decir que hayan perdido su vinculancia. Es obvio que las reglas siempre van a partir con ventaja sobre los principios, por cuanto un sistema sin normas nos retrotraería a la época de las cavernas donde imperaba la ley del más fuerte por la autocomposición de conflictos; hoy por hoy ello ha cambiado, a los magistrados solo les queda barajar las cartas y repartir de nuevo. Recién ahí podremos considerar que se han integrado plenamente al juego. 


\section{REFERENCIAS}

Alarcón Cabrera, C. y Vigo. R. (2011). Interpretación y Argumentación Jurídica. Problemas y Perspectivas Actuales. Buenos Aires: Marcial Pons.

Alexy. R. (2012) Teoría de los derechos fundamentales. Madrid: Centro de Estudios Políticos y Constitucionales.

Atienza, M. y García, J. (2018). Un debate sobre la ponderación. Sucre: Tribunal Constitucional Plurinacional de Bolivia. Academia Plurinacional de Estudios Constitucionales.

Atienza, M. (2013) Curso de Argumentación Jurídica. Madrid: Trotta.

Atienza, M. y Ruíz, J. (2011). Para una teoría postpositivista del derecho. Lima, Perú: Bogotá: Palestra, Temis.

Barak, A. (2017). Proporcionalidad. Los derechos fundamentales y sus restricciones. Lima: Palestra.

Da Rosa, T., García, J., y García, A., (2019.) Teoría de la Argumentación Jurídica. Principio de proporcionalidad y Racionalidad de las decisiones judiciales. Lima: Ediciones Legales.

Dworkin, R. (2012). Una cuestión de principios. Buenos Aires: Siglo XXI Editores

García, A., Gascón, M., Marcilla, G. y Prieto, L. (2014). Argumentación Jurídica. Valencia: Tirant Lo Blanch.

García, J. (2017). Decidir y argumentar sobre derechos. Ciudad de México: Tirant Lo Blanch.

Guastini, R. (2014). Interpretar y Argumentar. Madrid: Centro de Estudios Políticos y Constitucionales.

Guastini, R. (2014). La sintaxis del derecho. Madrid: Marcial Pons.

Martineau, F. (2010). Argumentación Judicial del abogado. Barcelona, España: Bosch 
Schecaira, F. y Struchiner, N. (2020) Teoría de la argumentación jurídica. Para entender el discurso de los jueces y abogados. Lima: Grijley.

Tribunal Constitucional del Perú (2006). La Constitución en la jurisprudencia del Tribunal Constitucional. Sentencias vinculadas con los artículos de la Constitución. Lima: Gaceta Jurídica.

Fecha de recepción: 10 de octubre de 2019

Fecha de aceptación: 11 de noviembre de 2019 